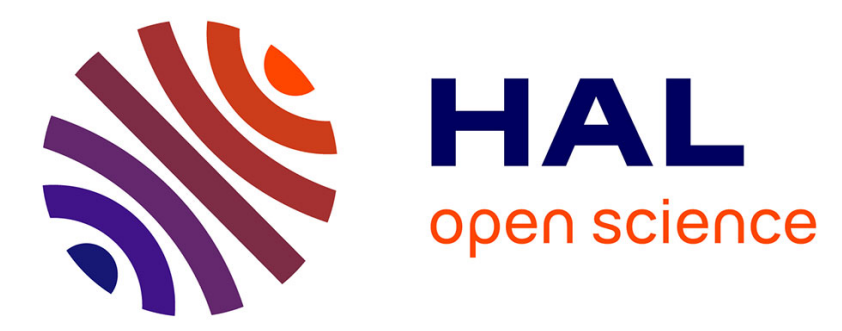

\title{
Topological insights into the $1 / 1$ diacetyl/water complex gained using a new methodological approach
}

\author{
D Dargent, E.-L Zins, B Madebène, Mohammad Esmaïl Alikhani
}

\section{To cite this version:}

D Dargent, E.-L Zins, B Madebène, Mohammad Esmail Alikhani. Topological insights into the 1/1 diacetyl/water complex gained using a new methodological approach. Journal of Molecular Modeling, 2015, 21 (8), pp.1-13. 10.1007/s00894-015-2751-9 . hal-01196789

\section{HAL Id: hal-01196789 \\ https://hal.sorbonne-universite.fr/hal-01196789}

Submitted on 10 Sep 2015

HAL is a multi-disciplinary open access archive for the deposit and dissemination of scientific research documents, whether they are published or not. The documents may come from teaching and research institutions in France or abroad, or from public or private research centers.
L'archive ouverte pluridisciplinaire HAL, est destinée au dépôt et à la diffusion de documents scientifiques de niveau recherche, publiés ou non, émanant des établissements d'enseignement et de recherche français ou étrangers, des laboratoires publics ou privés. 


\title{
A topological insight on the 1/1 : Diacetyl/Water complex through a new methodological approach
}

\author{
D. Dargent, ${ }^{1,2}$ E.-L. Zins, ${ }^{1,2}$ B. Madebène, ${ }^{1,2}$ and M.E. Alikhani. ${ }^{1,2, \dagger}$
}

${ }^{1}$ Sorbonne Universités, UPMC Univ. Paris 06, MONARIS, UMR 8233, Université Pierre et Marie Curie, 4 Place Jussieu, case courrier 49, F-75252 Paris Cedex 05, France.

${ }^{2}$ CNRS, MONARIS, UMR 8233, Université Pierre et Marie Curie, 4 Place Jussieu, case courrier 49, F-75252 Paris Cedex 05, France.

\footnotetext{
Abstract

The 1/1 : Diacetyl/Water complex is of atmospheric relevance. Previous experimental and theoretical studies were focused on two isomeric forms, and geometry optimizations were carried out.
}

Herein we propose a six-steps methodological approach based on topological properties for the search and the characterization of all the isomeric forms of a $1 / 1$ noncovalent complex: 1- a molecular electrostatic potential (MESP) study for an overview of the $\mathrm{V}_{\min }$ and $\mathrm{V}_{\max }$ regions on the molecular surfaces of the separated molecules; 2- a topological (QTAIM and ELF) study for a thorough characterization of the electron densities (QTAIM) and irreducible ELF basins of the separated molecules; 3- a fully optimization of guess structures based on the interaction between complementary reaction sites; 4- an energetic characterization based on a symmetry-adapted perturbation theory (SAPT) analysis; 5- a topological characterization of the optimized complexes; and 6- an analysis of the complexes in terms of orbital overlaps (natural bond orbitals, NBO analysis).

This approach was applied to the study of the $1 / 1$ : Diacetyl/Water complex. In addition with the topological characterization of two already-reported isomeric forms, a third possible isomer was identified and characterized.

\footnotetext{
${ }^{+}$Author to whom correspondence should be addressed. Pr. M. Esmaïl Alikhani CC 49, 4 place Jussieu, 75252 Paris (France) Electronic mail: esmail.alikhani@upmc.fr
} 


\section{Introduction}

Non-covalent interactions in general, and hydrogen bonding interactions in particular, are of fundamental importance in many fields such as biochemistry, catalysis and atmospheric chemistry [1]. This is probably one of the reasons why an effort was made since the first mention of hydrogen bondings, in the 1920's, to better characterize such interactions [2].

From a theoretical point of view, many efforts were made to improve the description of these interactions. These studies were not at all limited to a geometrical study of complexes. Rather, thorough investigations were carried out to describe these systems that are particularly challenging for the theoretical chemistry. Indeed, as (generally) non-covalent, weak, and largely electrostatic interactions, an accurate theoretical description of (classical) hydrogen bondings is far from obvious. A four-fold approach is now often applied to accurately describe hydrogen bondings: geometric, energetic, vibrational and topological parameters taken altogether allow a suitable description of the interactions [3,4]. Indeed, from a geometric point of view, the distances $\mathrm{X}-\mathrm{H}, \mathrm{H} \ldots \mathrm{Y}$ as well as the direct angle $\mathrm{X}-\widehat{\mathrm{H}} \cdot \mathrm{Y}$. are needed to characterize a hydrogen bonding between an $\mathrm{X}$ donor atom and an $\mathrm{Y}$ acceptor atom [5]. In the case of intermolecular interactions, the energy associated to the hydrogen bonding(s) can be calculated as the energetic difference between the complex and isolated isomers [6]. A decomposition of this interaction energy in terms of electrostatic interaction energy, exchange repulsion energy, delocalization and correlation energies, as given by a Symmetry-adapted perturbation theory (SAPT) analysis provides some insight on the nature of the interaction [7,8]. This method was widely applied in combination with Density Functional Theory (DFT) calculations (SAPT-DFT) [9] to characterize hydrogen bondings or, in a more classical way, in combination with ab initio (post Hartree-Fock) calculations.

Obviously, many studies focused on the electrostatic nature of the hydrogen-bond interaction. To that extend, hydrogen bondings have some common points with halogen bondings, chalcogen bondings and pnicogen bondings [10-13]. The prevalence of the electrostatic nature of these interaction motivated Politzer [14,15], Clark [16], and Grabowski $[17,18]$ to develop an approach based on the molecular electrostatic potential. They introduced the concept of $\sigma$-holes to rationalize the directionality of these interactions: " $\sigma$ holes are regions of positive molecular electrostatic potential collinear with and opposite to covalent bonds to atoms of Groups IV-VII" [16]. Since electrostatic attractions are a pivotal force in all these interactions, the electron density $\rho(r)$ can be used to characterize and predict these non-covalent interactions [19]. The molecular electrostatic potential can be calculated from the electron density $\rho(\mathrm{r})$ and the nucleic potential $\mathrm{V}_{\mathrm{N}}$ (Equation 1): 


$$
V(r)=V_{N}-\int \frac{\rho\left(r^{\prime}\right) d r^{\prime}}{r^{\prime}-r}
$$

\section{Equation 1}

In this equation, the expression the nucleic potential is given by :

$$
V_{N}=\sum_{i=1}^{N} \frac{Z_{i}}{\left|R_{i}-r\right|}
$$

\section{Equation 2}

where $Z_{i}$ represents the charges of each of the $i$ nucleus located at the $R_{i}$ position.

This concept was further extended to the study of crystals [20]. A $\sigma$-hole refers to a region of low electronic density that is collinear to a chemical bond or to a portion of a molecule. When such a region of low electronic density is perpendicular to portions of a molecular framework, the term " $\pi$-hole" is used [12,21].

Toward the electrostatic contribution on the hydrogen bondings, it was shown that dispersion interactions also play a prominent role in the formation of hydrogen-bonded complexes. More specifically, a symmetry-adapted perturbation theory (SAPT) study has shown that the size and the shape of substituants also strongly influence the stabilization of hydrogen-bonded complexes [22].

In addition, the Quantum Theory of Atoms in Molecules (QTAIM) approach allows a precise characterization of these interactions [23]. According to the QTAIM, "the quantum mechanics of proper open systems yields the physics that governs the local behavior of the electron density, $\rho(r)$. All bond paths, lines of maximum density linking neighboring nuclei in a system in stable electrostatic equilibrium, have a common physical origin. The presence of a bond path and its associated virial path provide a universal indicator of bonding between the atoms so linked" [24]. The charge density, $\rho(r)$, is a well-defined physical quantity that has a defined value at each point of the three-dimensional direct space. Moreover, the topology of the charge density, $\rho(\mathrm{r}$ ), allows one to define bond paths and critical points (where $\nabla \rho=0$ ).

The Laplacian of $\rho, \nabla^{2} \rho$, at the critical point measures to what extent the electron density is locally depleted if $\nabla^{2} \rho>0$ (associated with closed-shell interactions, such as ionic bonds, hydrogen bonds, and van-der-Waals molecules, etc.), or concentrated if $\nabla^{2} \rho<0$ (associated with shared interactions, such as dative or covalent bonds) [23].

A systematic study on complexes representing different types of hydrogen bonds allowed to characterize the covalent or non-covalent nature of these interactions. Three families of hydrogen bondings were defined based on the energetic decomposition of the theory of the intermolecular interaction in combination with the QTAIM approach [17,25]:

covalent interactions, in systems such as $[\mathrm{FHF}]^{-}$, 
partially covalent interactions, for instance in the case of the $\mathrm{HCOOH}$ dimer, and non-covalent interactions as they exist in the water dimer.

Complementarily, the Electron Localization Function (ELF) also proved to be a powerful approach to investigate hydrogen bondings [26-29]. This topological approach is based on the probability of finding an electron with a given spin in the vicinity of another electron with the same spin. This probabilistic approach leads to the definition of basins and attractors.

The topology of the ELF gradient field evidences two types of basins: the core basins around nuclei with $Z>2$ and the valence basins in the remaining space [30]. These basins closely match the electronic domains defined by Gillespie in the VSEPR model, and therefore the ELF gradient field topology provides a reliable mathematical model for Lewis valence theory as well as for VSEPR. The core basins are denoted by C(A) where A stands for the atomic symbol of the atom to which it belongs whereas $\mathrm{V}(\mathrm{A}, \mathrm{B})$ denotes a valence basin shared by the A and B atomic centers. Moreover, the valence basins are characterized by their synaptic order defined as the number of core basins with which a given valence basin shares boundaries. By integrating the one-electron density over any of the core or valence basin volumes we calculate their populations, $\mathrm{N}(\Omega \mathrm{i})$ which can be alternatively defined as the expectation values of the basin population operators. The closure relation of the basin population operators enables statistical analysis of the basins populations to be carried out through the definition of a covariance matrix [31]. A valence basin is a reducible ELFlocalization domain when it contains more than one attractor. Irreducible basins, surrounding one attractor, can be identified upon the increase of the value of the ELF function, $\eta(\mathrm{r})$. The ELF partition was further applied to the study of hydrogen bondings [32-34].

Diacetyl (DAC) is formed in the atmosphere as a result of degradation of hydrocarbons released in the atmosphere in urban and industrial areas [35,36]. Hydrated diacetyl-water clusters may be subsequently formed and affect the complex atmospheric chemistry [37,38], involving $\mathrm{HO}_{\mathrm{x}}$ and other radicals [39-41]. The 1/1: DAC/ $\mathrm{H}_{2} \mathrm{O}$ complex was experimentally studied in the context of an atmospherically-relevant study, by Mucha and Mielke [42]. Their work also included a theoretical investigation by means of ab initio Møller-Plesset calculations, and three different isomers were proposed for this complex. This pioneering study was subsequently completed by a rotational investigation [43]. These two studies almost resulted in the characterization of two distinct isomers, in terms of geometric and energetic parameters and rotational constants. 
Following our interest in hydrated complexes atmospherically-relevant [44], we realized that a global methodological approach for the determination of all the isomeric forms of a non-covalent complex was missing. Herein we would like to propose such an approach for the identification and the characterization of non-covalent complexes. To exemplify our approach, we were looking for a simple hydrated dimer $\mathrm{H}_{2} \mathrm{O}$-A fulfilling the following criteria:

$>$ experimental data should be available in the literature,

$>$ different hydrogen-bond donor and acceptor sites should be available on the molecule A,

$>$ the A partner should be a small, well characterized molecule, that may be present in the atmosphere,

$>$ the formation of larger complexes $\mathrm{A}\left(\mathrm{H}_{2} \mathrm{O}\right)_{2}$ should be possible.

The $1 / 1$ : brunoDAC/ $\mathrm{H}_{2} \mathrm{O}$ complex fulfills all these criteria. Furthermore, even if a theoretical study was reported on this complex, a topological characterization was missing.

To further theoretically characterize the different isomeric forms of the $1 / 1$ : DAC/ $\mathrm{H}_{2} \mathrm{O}$ complex, our investigation was as follows:

1. First of all, a molecular electrostatic potential analysis was carried out on the isolated molecules. This approach allows to locate the different interaction sites and to specify their chemical nature.

2. The QTAIM and ELF allow the characterization of domains that are rich or poor i) in term of electron density, and ii) in term of paired electron density, respectively. These results enable us to rationalize the chemist's concepts of electrophilic and nucleophilic sites.

3. From these initial studies, guess structures for the $1 / 1: \mathrm{DAC} / \mathrm{H}_{2} \mathrm{O}$ complexes were constructed and fully optimized with a reference level of theory, $\operatorname{CCSD}(\mathrm{T})$ F12/AVDZ. Additionally, MP2/AVTZ calculations were carried out.

4. The QTAIM approach was used to characterize the interactions by means of bond critical points and ring critical points.

5. SAPT analysis were carried out to characterize the nature of the non-covalent interaction in terms of electrostatic, exchange, induction and dispersion energies.

6. The complexes were also characterized in term of orbital overlaps by means of the Natural Bond Orbital (NBO) approach. 
The steps 1, 3, 4, 5 and 6 constitute a now well-established procedure for the location and characterization of the interaction sites $[45,46]$. On the other hand, in the present case, the addition of the step 2 was helpful prior to the construction of guess structures.

First, a brief comparison between previous investigations on the $1 / 1: \mathrm{DAC} / \mathrm{H}_{2} \mathrm{O}$ complex, and on smaller hydrated complexes of diatomic species, is proposed. The motivation of the present investigation is then presented. The results are further presented following the above-mentioned steps.

\section{Previous results and outstanding issues}

In 2012, Schaeffer III et al.[47] reported the study of 1/1 complexes between water molecule and three different isovalent diatomic species: $\mathrm{CO} / \mathrm{H}_{2} \mathrm{O}[48], \mathrm{CS} / \mathrm{H}_{2} \mathrm{O}$ and $\mathrm{SiO} / \mathrm{H}_{2} \mathrm{O}$. Isomers in which the $\mathrm{O}-\mathrm{H}$ bond of the water molecule is almost parallel with the diatomic molecule were found. Such structures cannot be attributed to the formation of an hydrogen bonding. Indeed, hydrogen bondings are known to be directional, and an angle close to $180^{\circ}$ is expected between the hydrogen donor bond, the hydrogen atom, and the hydrogen acceptor atom. On the other hand, structures in which the $\mathrm{O}-\mathrm{H}$ bond of the water molecule is almost parallel with the diatomic molecule may be connected with the $\pi$-hole bonding concept $[12,21]$.

In the case of the $\mathrm{CO} / \mathrm{H}_{2} \mathrm{O}$ complex, three stable isomers were theoretically characterized by Wheathley and Harvey (Table 1). On the other hand, to the best of our knowledge, no topological characterization of these complexes was reported, and such a study would be necessary to confirm the presence of a $\pi$-hole bonding.

As aforementioned, two main experimental and theoretical studies were carried out on the $1 / 1: \mathrm{DAC} / \mathrm{H}_{2} \mathrm{O}$ complex. Three structures in which the water molecule acts simultaneously as an hydrogen-bonding donor (toward the oxygen atom of the carbonyl group) and as an hydrogen-bonding acceptor for methyl hydrogen atoms, were proposed (Table 1). These isomers will be denoted I, IIa and IIb, respectively.

Additionally, another isomer may be expected for the $\mathrm{DAC} / \mathrm{H}_{2} \mathrm{O}$ complex, based on comparisons with the $\mathrm{CO} / \mathrm{H}_{2} \mathrm{O}$ isomers. Indeed, the carbonyl group present in the DAC molecule may lead to the formation of a $\pi$-hole centered on the carbon atom of the carbonyl group. An analysis based on the molecular electrostatic potential is needed to further characterize such an electronic deficient region. If its existence is confirmed, another structure may be proposed in which one $\mathrm{O}-\mathrm{H}$ bond of $\mathrm{H}_{2} \mathrm{O}$ interacts with one of the two OC bonds of DAC. 


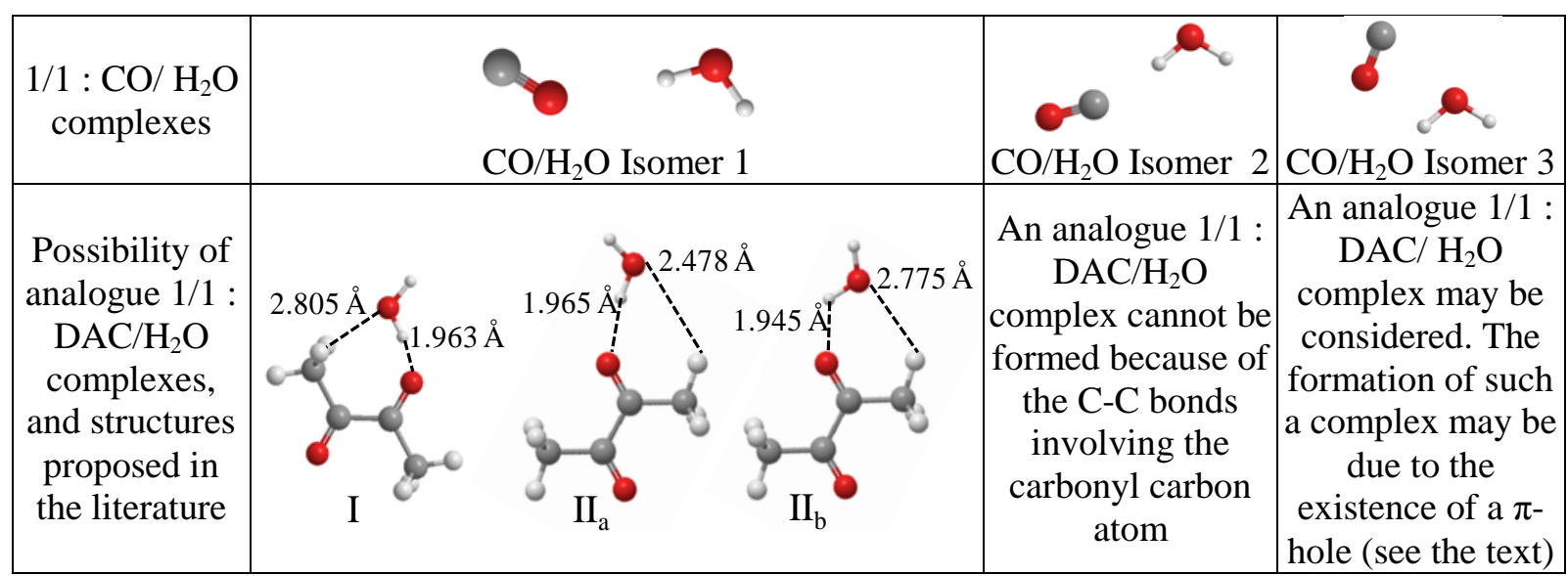

Table 1: Structures proposed in the literature for the $1 / 1: \mathrm{CO} / \mathrm{H}_{2} \mathrm{O}[48]$ and $1 / 1: \mathrm{DAC} / \mathrm{H}_{2} \mathrm{O}[42]$ complexes. The comparison between the isomers proposed in the literature for these two complexes suggests the existence of another $1 / 1: \mathrm{DAC} / \mathrm{H}_{2} \mathrm{O}$.

\section{Characterizations of the isolated monomers}

\section{A. Electrostatic potential}

The molecular electrostatic potential (MESP) allows to describe the molecular surface. It is now well established that the net atomic charge model cannot account for the formation of non-covalent interactions such as halogen bondings and pnicogen bondings, because an atom is not always uniformly charged. This charge distribution can lead to a topological description of the molecular space. It was shown that such a description is particularly suitable in the case of hydrogen bondings since it allows to rationalize the directionality of this interaction. This was achieved by introducing the $\sigma$-hole concept: the formation of a $\sigma$ bond can lead to a depletion of electrons in the opposite direction. Such an anisotropy in the molecular electrostatic potential may favor interactions with a lone pair of a Lewis base or an anion. This phenomenon was first pointed out in the case of halogen bondings [49]. The concept was the extended to covalently-bonded atoms of groups IV-VII [50,51].

Additionally, the concept of $\pi$-hole was introduced more recently, to describe situations in which a local depletion of electrons is perpendicular to a chemical bond [12,21]. Even if such situations are less often reported, the formation of chalcogen bondings may be explained by means of $\pi$-holes.

Accordingly, the MESP analysis allows to distinguish the axial and facial electronic deficient regions around an atom on the molecular surface. These outer portions appointed as $\sigma$ - and $\pi$ holes[51] are characterized by a positive electrostatic potential (color code: blue region) where the potential value is maximum, $\mathrm{V}_{\max }$. It is also interesting to note that the outer portions colored in red, where the potential value is minimum $\mathrm{V}_{\min }$, are indicative of the presence of the charge concentration (lone pair, etc) [52]. 
A

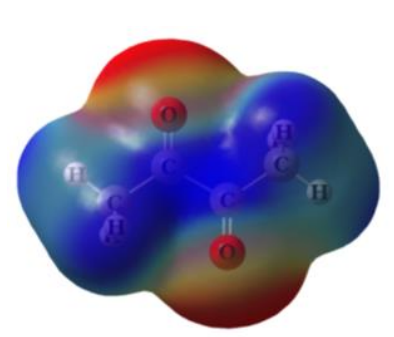

B

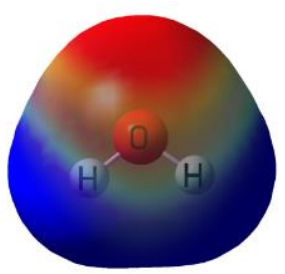

Figure 1: Molecular electrostatic potential mapped on the molecular surfaces for the DAC (A) and water (B) molecules. (MP2/AVTZ)

The overall electrostatic potential of the DAC molecule was computed on the 0.001electron/bohr [13] molecular surface (Figure 1). This study allows the characterization of regions that may act as electron acceptors and electron donors, respectively. More specifically, and as would be anticipated, the most negative electrostatic potential on the DAC and on the water surfaces are associated with oxygen atoms. On the DAC surface, the carbon atoms of the carbonyl groups are characterized by a positive electrostatic potential. On the water surface, a very strongly positive electrostatic potential on the hydrogen atoms indicates their propensity toward the formation of hydrogen bondings.

This simple characterization suggests that electrostatic-driven non-covalent interaction between DAC and water may lead to the formation of complexes. In addition with the formation of "classical" hydrogen bondings, a complex due to the formation of a $\pi$-hole bonding may be expected. On the other hand, a further accurate description is needed in order to propose guess geometries for a 1/1 complex.

\section{B. Further topological characterization of the isolated monomers}

We would like to point out that, for simpler systems, the determination of the MESP of each isolated monomer may be sufficient to propose geometries for $1 / 1$ complexes.

On the other hand, in the present case, the MESP approach was sufficient for a global identification of electron-rich $\left(\mathrm{V}_{\min }\right)$ and electron-poor $\left(\mathrm{V}_{\max }\right)$ regions, but not for a precise location of the interaction sites. A combined QTAIM/ELF topological characterization unambiguously leads to guess structures for the 1/1 complex. The contour maps of the Laplacian of the electron density distributions for the DAC are shown in Figure 2. In the plane defined by the oxygen and carbon atoms (Figure 2A), two electron-rich domains appear on the oxygen atoms of each carbonyl group, corresponding to the Chemist's intuition based on the Lewis structures, with the two lone pairs of electrons located on these oxygen atoms. 
Furthermore, The contour maps of the Laplacian of the electron density $\nabla^{2} \rho$ clearly shows that the four carbon atoms are electron depleted, thus suggesting that they may have electrophilic properties. Orthogonally to this plane (Figure 2B), the carbon atom of the carbonyl group are characterized by a particularly electron-poor region, as shown for one of the carbonyl group. This could be considered as the QTAIM image of the $\pi$-hole. Thus, complementarily to the MESP analysis, the QTAIM characterization of the DAC monomer allows a precise location of electron-rich and electron-poor regions. Furthermore, expected $\pi$ holes (see part 3A) are indeed present in the DAC molecule, on each of the carbon atom of the carbonyl group.

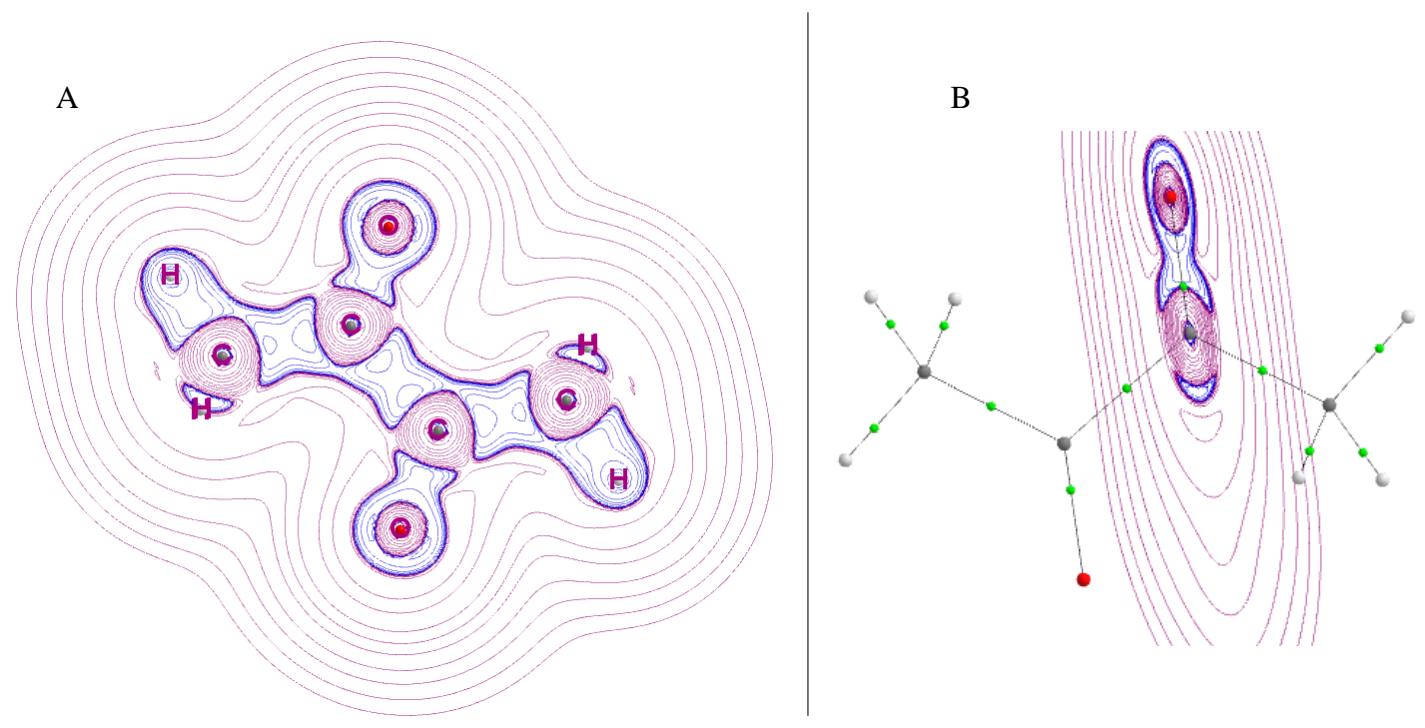

Figure 2: Contour map of the Laplacian of the electron density $\nabla^{2} \rho$ A: in the plane of the carbon and oxygen atoms; $B$ : orthogonally to this plane around one of the carbonyl group. (MP2/AVTZ)

Additionally, Table 2 presents the basins of the ELF function. In addition with hydrogen basins plotted in cyan, the figures allows the identification of reducible domains in which the probability of finding an electron with a given spin in the vicinity of another electron with the same spin is high (in green), medium (in blue) or particularly low. It is important to underline that several figures are needed to totally describe the ELF function on the surface of the DAC molecule. Indeed, when the cutoff value of the ELF function is low, domains lacking paired electrons can be identified on carbon carbonyl atoms. Complementarily, plots with high ELF cutoff values are helpful in the precise location of paired electron rich domains on oxygen carbonyl atoms. 
More precisely, a plot of the ELF value that corresponds to the electron gas $(0.50)$ allows a characterization of (tiny) domains lacking paired electrons on carbon atoms of the carbonyl groups. When the cutoff value of the ELF function is slightly increasing, up to 0.55 , the presence of such reduced domains lacking paired electrons on carbon atoms of the carbonyl groups is confirmed. For such low values of the ELF function, each oxygen atom of the carbonyl groups is characterized by a unique paired electron rich basin. When the cutoff value of the ELF function is still increasing, up to 0.75, the shape of the basins around the oxygen atoms of the carbonyl groups change, but this value is not sufficient to characterize the pairs of free electrons as would be expected from the Lewis structure. On the other hand, when the cutoff value of the ELF function is set at 0.89, two isolated irreducible basins are characterized on each oxygen atom of the carbonyl groups, thus suggesting that an electrostatic interaction involving these oxygen atoms will be highly directional. Similar basins are characterized with a cutoff value of the ELF function set at 0.90 .

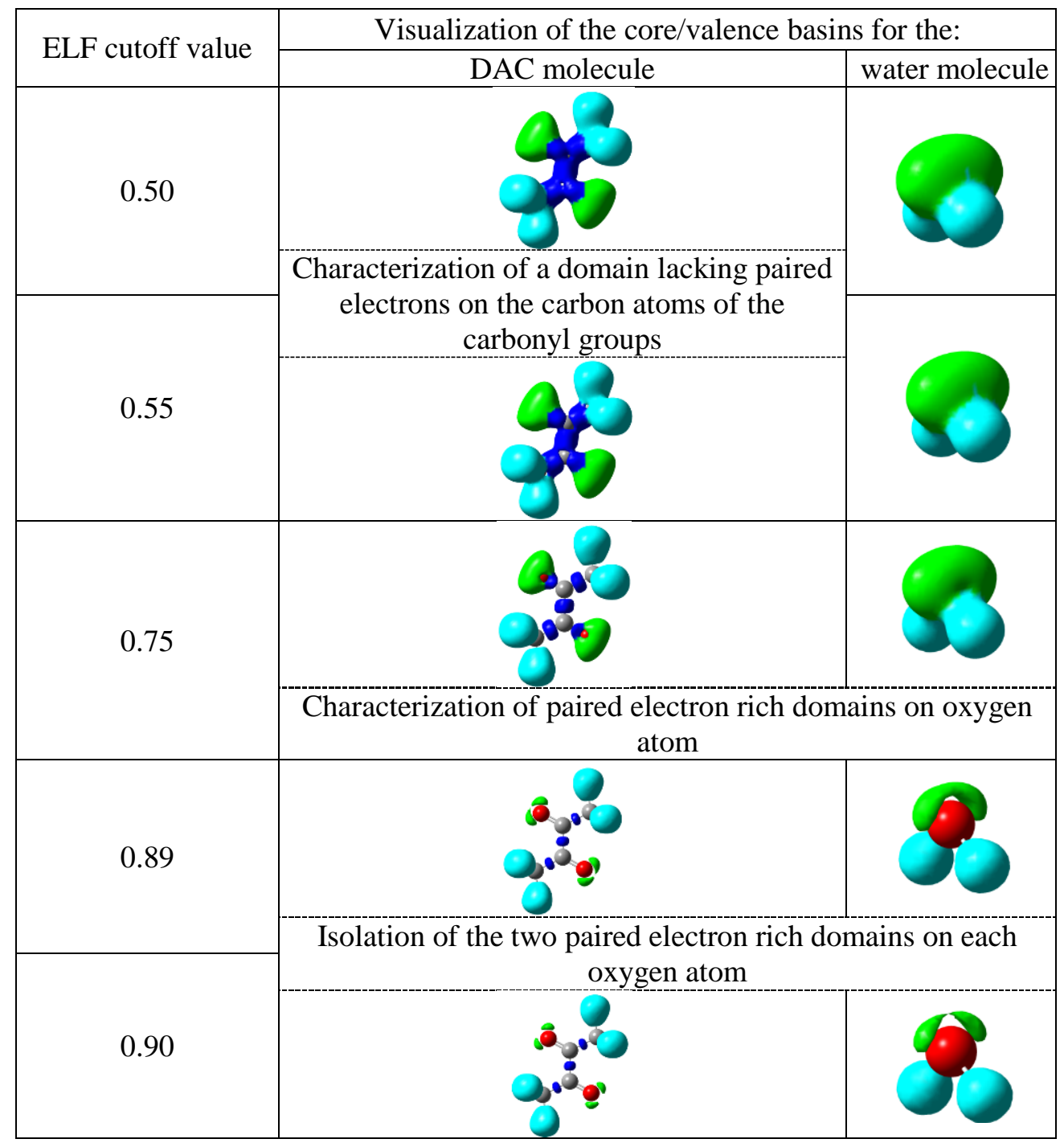


Table 2: Characterization of irreducible ELF basins on the DAC and water molecules.

Depending on the cutoff value of the ELF function, electrophillic or nucleophillic domains can be identified. (See text) (MP2/AVTZ)

For a sake of comparison, basins of the water molecule were determined at the same values of the ELF function. A unique basin corresponding to the lone pairs of the oxygen atom, apperas for a cutoff value of the ELF function of 0.89 . This basin begins to split into two irreducible basins for a cutoff value of 0.90 .

Finally, Scheme 1 presents the localization domain reduction tree diagrams [29] for the DAC (Scheme 1A) and water (Scheme 1B) [53] molecules.

A

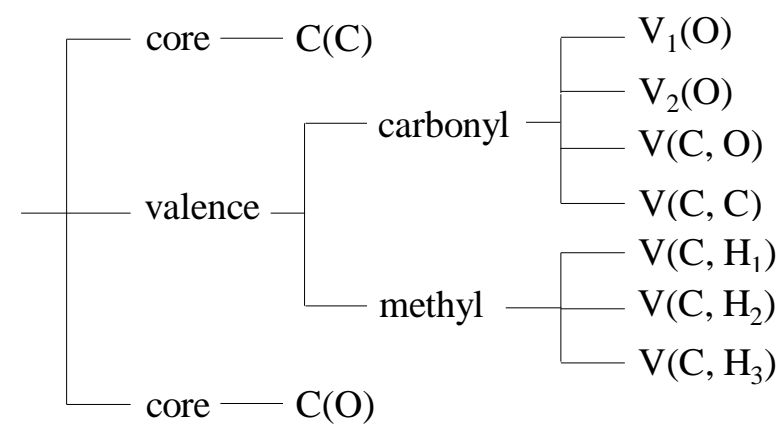

B

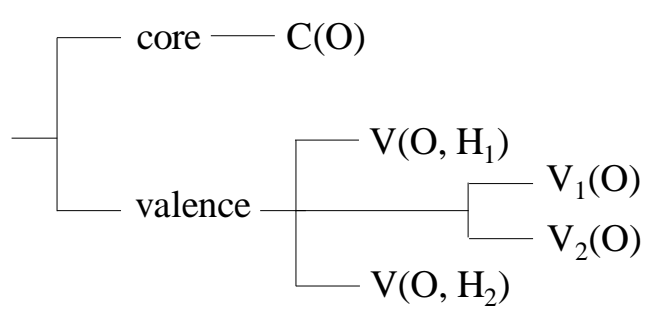

Scheme 1: localization domain reduction tree diagram for the A: DAC and B: Water [53] molecules.

\section{Characterization of different isomers for the $1 / 1$ : $\mathrm{DAC} / \mathrm{H}_{2} \mathrm{O}$ complex}

\section{A. Proposition of guess structures}

This thorough topological characterization allows a precise location of $\mathrm{V}_{\min }$ and $\mathrm{V}_{\max }$ regions. Thus, guess structures form the $1 / 1: \mathrm{DAC} / \mathrm{H}_{2} \mathrm{O}$ complex can be built up based on possible interactions between $\mathrm{V}_{\min }$ regions from one molecule and $\mathrm{V}_{\max }$ regions from the other one. The more stabilizing interactions, the more the isomers should be stable. Accordingly, one can suggest three different available sites for an hydration process of the DAC molecule, namely S1, S2 and S3, presented in Figure 3. 


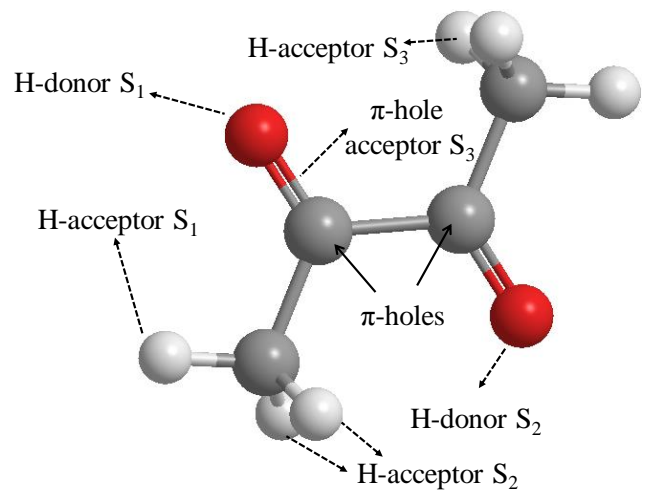

Figure 3: The different sites available for an hydration process of the DAC molecule.

Thus, complementary to the results already published, an additional isomer (S3) may be expected for the $1 / 1: \mathrm{DAC} / \mathrm{H}_{2} \mathrm{O}$ complex, involving an interaction between a $\mathrm{V}_{\text {min }}$ region from the water molecule (lone pair basin) and a $\mathrm{V}_{\max }$ region from the carbonyl group of the DAC molecule ( $\pi$-hole).

\section{B. Geometry optimization and energetic characterization of the different isomers}

The three different isomers were built up and fully optimized at the $\operatorname{CCSD}(\mathrm{T})$ F12/AVDZ level of theory [54,55] (Figure 4). This level of theory was chosen as reference calculations for energetic and geometric characterization. Geometry optimizations were also carried out at the MP2/AVTZ level of theory for a sake of comparison. Similar results were obtained at both levels of calculations (Table 3). Optimized structures for both monomers and 1/1 : DAC/Water isomers are reported in the supplementary material (SM1) [56].

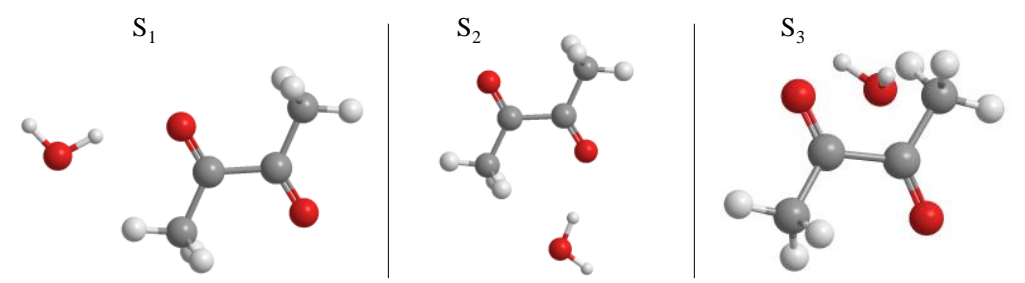

Figure 4: Three different isomers for the 1/1 : $\mathrm{DAC} / \mathrm{H}_{2} \mathrm{O}$ complex optimized at the CCSD(T)F12/AVDZ level of theory.

The binding energies calculated at MP2 level is almost the same as those obtained at the reference level of theory. We also reported the zero-point-vibrational-energy corrected binding energy with the MP2/AVTZ method. It is noteworthy that the three isomers are actually isoenergetic. They could be considered as the non-covalent species with medium strength. 
Globally, the stabilization energy associated to the formation of the $1 / 1$ complex is in the $(20 \pm 5) \mathrm{kJ} / \mathrm{mol}$ range, for the three considered isomers.

\begin{tabular}{|c|cc|cccc|}
\hline \multirow{2}{*}{ Species } & \multicolumn{2}{|c|}{ CCSD(T)-F12/AVDZ } & \multicolumn{4}{|c|}{ MP2/AVTZ } \\
\cline { 2 - 7 } & $\begin{array}{c}\mathrm{E} \\
\text { (a.u.) }\end{array}$ & $\begin{array}{c}\text { De } \\
(\mathrm{kJ} / \mathrm{mol})\end{array}$ & $\begin{array}{c}\mathrm{E} \\
\text { (a.u.) }\end{array}$ & $\begin{array}{c}\mathrm{E}(\mathrm{ZPE}) \\
\text { (a.u. })\end{array}$ & $\begin{array}{c}\mathrm{D}_{\mathrm{e}} \\
(\mathrm{kJ} / \mathrm{mol})\end{array}$ & $\begin{array}{c}\mathrm{D}_{0} \\
(\mathrm{~kJ} / \mathrm{mol})\end{array}$ \\
\hline $\mathrm{DAC}$ & -306.052837 & & -305.937863 & -305.844044 & \\
$\mathrm{H}_{2} \mathrm{O}$ & -76.352163 & & -76.328992 & -76.307582 & & \\
$\mathrm{~S}_{1}$ & -382.414365 & -24.6 & -382.276258 & -382.158303 & -24.7 & -17.5 \\
$\mathrm{~S}_{2}$ & -382.414400 & -24.7 & -382.276301 & -382.158281 & -24.8 & -17.5 \\
$\mathrm{~S}_{3}$ & -382.413240 & -21.6 & -382.275166 & -382.157805 & -21.8 & -16.2 \\
\hline
\end{tabular}

Table 3: Total energies $(E)$, binding energies $\left(D_{e}\right)$ and ZPE corrected binding energies $\left(D_{0}\right)$ associated to the studied isomers $S_{1}, S_{2}$ and $S_{3}$, calculated at two different levels of theory.

Further energetic characterization in terms of electrostatic interaction energy, exchange repulsion energy, delocalization and correlation energies, (SAPT analysis) was carried out at the (SAPT-DFT) [9] level of theory, as implemented in the Molpro package, using the PBE0 density functional. The different contributions to the total stabilization energy of the dimers are presented in Table 4. For a sake of comparison, the values corresponding to the water dimer are also given [22]. The percentage contributions of the different energetic components to the total stabilization energy of these species are shown in Figure 5. The electrostatic, exchange, induction and dispersion contributions are globally similar for the three isomers. More precisely, the electrostatic energy is always predominant toward the dispersion energy. However, we note in passing from an energetic point of view that $S_{1}$ and $S_{2}$ are almost identical: their stabilization energy are similar, and the SAPT analysis leads to a very close energetic decomposition. The $S_{3}$ isomer appears to be slightly different from these criteria: its stabilization energy is slightly lower, and the electrostatic and exchange contribution on the stabilization of the complex are slightly smaller in absolute values. 


\begin{tabular}{lcccc}
\hline & $\mathrm{S}_{1}$ & $\mathrm{~S}_{2}$ & $\mathrm{~S}_{3}$ & $\left(\mathrm{H}_{2} \mathrm{O}\right)_{2}$ \\
\hline $\mathrm{E}_{\text {elst }}(\mathrm{kJ} / \mathrm{mol})$ & -39.8 & -36.8 & -28.8 & -35.2 \\
$\mathrm{E}_{\text {exch }}(\mathrm{kJ} / \mathrm{mol})$ & +47.0 & +43.6 & +33.6 & 37.5 \\
$\mathrm{E}_{\text {ind }}(\mathrm{kJ} / \mathrm{mol})$ & -6.9 & -6.3 & -3.4 & -5.6 \\
$\mathrm{E}_{\text {disp }}(\mathrm{kJ} / \mathrm{mol})$ & -13.5 & -13.7 & -14.1 & -8.4 \\
$\mathrm{E}_{\mathrm{SAPT}}=\Sigma \mathrm{E}_{\mathrm{i}}(\mathrm{kJ} / \mathrm{mol})$ & -13.2 & -13.3 & -12.6 & -11.6 \\
Corrected De $(\mathrm{kJ} / \mathrm{mol})$ & -17.6 & -17.2 & -14.5 & -15.5 \\
$\mathrm{E}_{\text {disp }} / \mathrm{E}_{\text {elst }}$ & $34 \%$ & $37 \%$ & $49 \%$ & $24 \%$ \\
\hline
\end{tabular}

Table 4: SAPT-DFT analysis of the $1 / 1 \quad$ : $\mathrm{DAC} / \mathrm{H}_{2} \mathrm{O}$ isomers at the PBE0/6311++G(2d,2p)//MP2/AVTZ level of theory. Both $E_{\text {ind }}$ and $E_{\text {disp }}$ are corrected with their exchange counterpart, $E_{\text {exch_ind }}$ and $E_{\text {exch_disp }}$ respectively

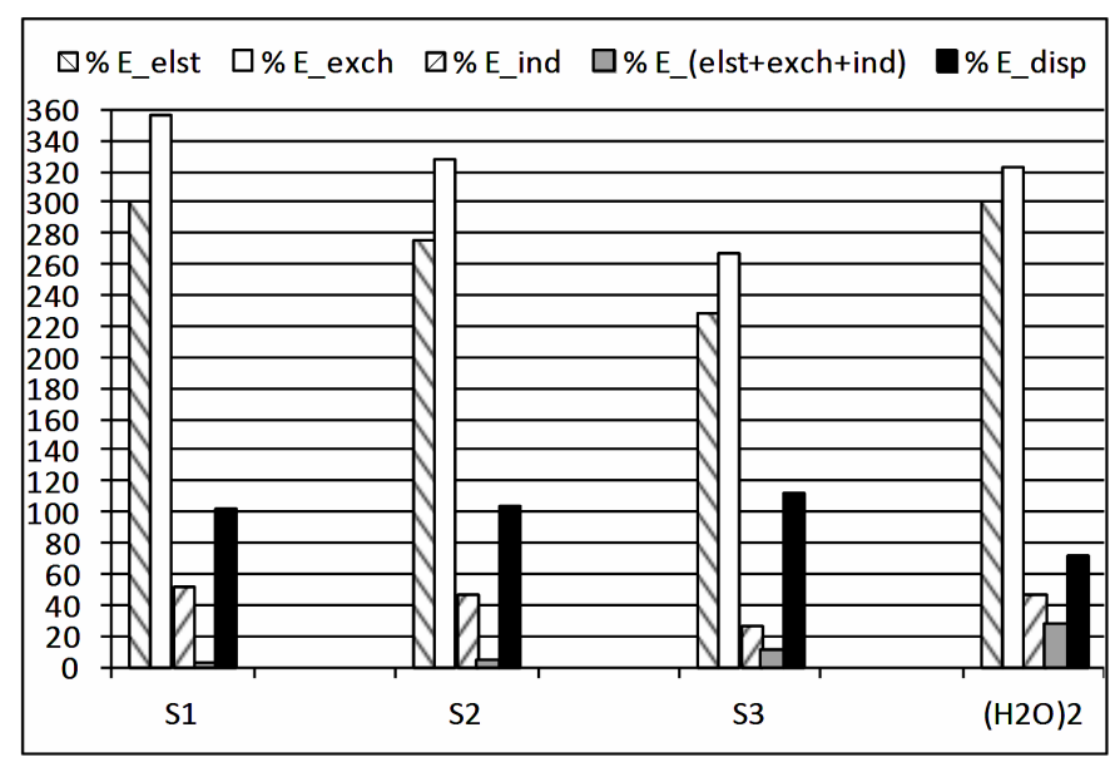

Figure 5: Absolute values of the percentage contributions to the total stabilization energies of the dimers.

\section{Topological characterization of the isomers for the 1/1:DAC/H ${ }_{2} \underline{O}$ complex}

To further characterize the interactions between the water and the DAC molecules in each of the considered isomers, a QTAIM topological investigation was carried out (Figure $6)$.

In the $S_{1}$ isomer, the optimized geometry suggests that the water and the DAC molecules simultaneously act as hydrogen bond donor and hydrogen acceptor, thus leading to a cyclic structure. This is confirmed by the QTAIM study (Figure 6A): the topological 
characterization of this isomer indeed leads to the identification of two BCP and one ring critical point (RCP).

As far as the $S_{2}$ isomer is concerned, the situation is a little bit more complex: from the optimized geometry, the interaction between water and DAC molecules may appear to be globally similar to what was calculated for the $S_{1}$ isomer. Nevertheless, this isomer is topologically characterized by three BCP and two RCP. Indeed, the oxygen atom of the water molecule is simultaneously in interaction with two methyl hydrogen atoms of the DAC molecules, whereas one of the oxygen atom of the carbonyl group of the DAC molecule forms an hydrogen bonding with one of the hydrogen atom of the water molecule. Thus, the difference between $S_{1}$ and $S_{2}$ rely on the formation of one or two hydrogen bondings between the methyl hydrogen atoms of the DAC molecules and the water oxygen atom, respectively. Moreover, the descriptions of the BCP's and RCP's in these two isomers are very similar in terms of electron densities, Laplacian and bond ellipticities values (Table 5).

Furthermore, we would like to emphasize the need of the "Density = Current" keyword in the route instruction of input file for QTAIM analysis from Gaussian09 calculations. Indeed, without this keyword, the analysis is carried out with the SCF density. Whereas this often only leads to slightly changes in the characterization of BCP and RCP, in the present work, the use of the SCF density leads to the identification of only two BCP and one RCP for both $\mathrm{S}_{1}$ and $\mathrm{S}_{2}$ isomers. This calculation artifact is due to a lack of accuracy of the electron density calculated at the Hartree-Fock level, even from an accurately determined geometry. 

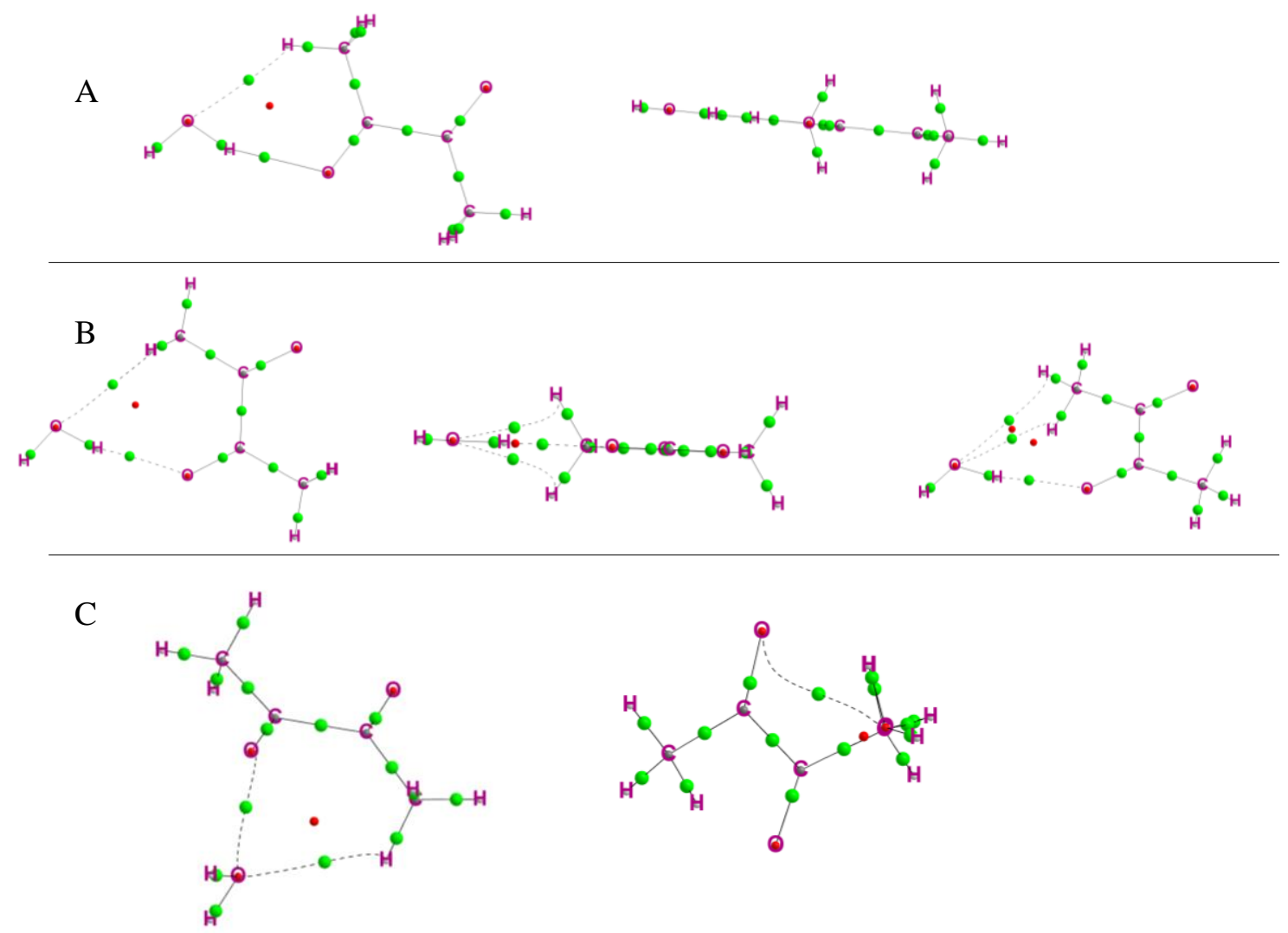

Figure 6: Topological QTAIM characterization of three isomers for the 1/1 : $\mathrm{DAC} / \mathrm{H}_{2} \mathrm{O}$ complex. BCP's and RCP's are indicated in green and in red circles, respectively, for the $A: S_{1}, B: S_{2}$ and $C: S_{3}$ isomers. The wfn function has been calculated at the CCSD/AVTZ//CCSD(T)-F12/AVDZ level.

As would be expected from the geometry of the three considered isomers, the topological characterization of $\mathrm{S}_{3}$ is clearly different than the one of the two previous isomers: one $\mathrm{BCP}$ is found between a methyl hydrogen atom of the DAC molecule and the water oxygen atom, and another one between the oxygen atom of the carbonyl group of the DAC molecule and the water oxygen atom. Thus the water oxygen atom is involved simultaneously in each of the two BCP's that characterize this isomer. The resulting cyclic structure leads to the definition of an unique RCP. Whereas the identification of a BCP between a methyl hydrogen atom of the DAC molecule and the water oxygen atom was expected from the geometry of the isomer, the location of the second $\mathrm{BCP}$, between two oxygen atoms, is rather surprising. To the best of our knowledge of the literature, no BCP has been reported between two oxygen atoms in the context of non-covalent interactions of hydrated complexes.

To further ascertain that this BCP is not an artifact that would be due to the geometry of the complex between the water and the DAC molecule, topological calculation were 
carried out on the hydrated diatomic complexes $\mathrm{CO} / \mathrm{H}_{2} \mathrm{O}$ (not shown) and $\mathrm{SiO} / \mathrm{H}_{2} \mathrm{O}$ investigated by Schaeffer et al.[47] Results are presented in Figure 7 in the case of the most stable $1 / 1: \mathrm{SiO} / \mathrm{H}_{2} \mathrm{O}$ isomer. A topological characterization similar to the one obtained for the $\mathrm{S}_{3}$ isomer, with a BCP located between two oxygen atoms, is calculated (Figure 7A). In terms of molecular orbitals, the electron transfer takes place from a $\sigma$-orbital of the water molecule ( $\sigma$ lone-pair of oxygen) to an unoccupied $\pi^{*}(\mathrm{CO})$ orbital (Figure 7B).
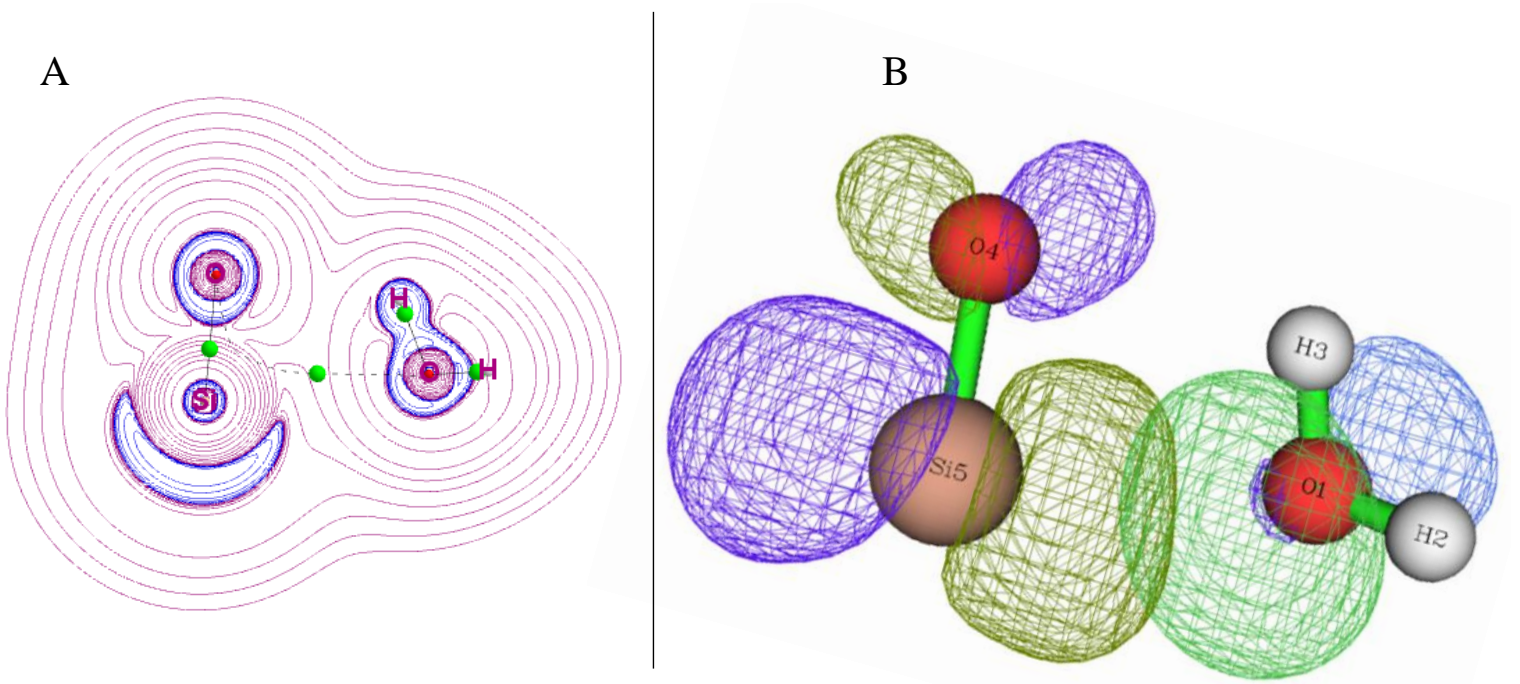

Figure 7: Characterization of the most stable isomer for the $1 / 1: \mathrm{SiO} / \mathrm{H}_{2} \mathrm{O}$ complex. A: QTAIM topological characterization, the BCP's are indicated in green; B: NBO molecular orbitals overlap. (CCSD/AVTZ//CCSD(T)-F12/AVDZ)

Thus, the oxygen - oxygen BCP is not an artifact due to the geometry of the $\mathrm{S}_{3}$ isomer [57]. Furthermore, the interactions involved in this hydrated isomer are clearly different in their natures than the ones involved in the two other isomers. Moreover, the topological characterization of the BCP's and RCP in terms of electron densities, Laplacian and bond ellipticities values are clearly different to what was calculated for the two other isomers (Table 5). It is interesting to note that the bond ellipticity associated to the oxygen-oxygen BCP is particularly high, thus underlying the non-linearity of the interaction.

\begin{tabular}{|l|l|l|l|l|}
\hline \multicolumn{2}{|l|}{ Critical Points } & S1 & S2 & S3 \\
\hline \multirow{3}{*}{$B C P$} & $\rho\left(\mathrm{H}_{\text {water }}-\mathrm{O}_{\text {carbonyl }}\right) ; \nabla^{2} \rho ; \varepsilon$ & $0.023 ; 0.08 ; 0.0$ & $0.022 ; 0.09 ; 0.0$ & Non BCP \\
\cline { 2 - 5 } & $\rho^{\text {BCP }}\left(\mathrm{O}_{\text {water }}-\mathrm{O}_{\text {carbonyl }}\right) ; \nabla^{2} \rho ; \varepsilon$ & Non BCP & Non BCP & $0.011 ; 0.05 ; 2.0$ \\
\cline { 2 - 5 } & $\rho\left(\mathrm{O}_{\text {water }}-\mathrm{H}_{\text {methyl }}\right) ; \nabla^{2} \rho ; \varepsilon$ & $0.009 ; 0.04 ; 0.2$ & $0.006 ; 0.03 ; 1.6$ & $0.007 ; 0.03 ; 0.3$ \\
\hline \multirow{2}{*}{ RCP } & $\rho\left(1^{\text {st }}\right.$ cycle $) ; \nabla^{2} \rho$ & $0.007 ; 0.04$ & $0.005 ; 0.03$ & $0.006 ; 0.02$ \\
\cline { 2 - 6 } & $\rho\left(2^{\text {nd }}\right.$ cycle $) ; \nabla^{2} \rho$ & Non RCP & $0.006 ; 0.03$ & Non RCP \\
\hline
\end{tabular}


Table 5: The QTAIM parameters in the $1 / 1: \mathrm{DAC} / \mathrm{H}_{2} \mathrm{O}$ isomers. Star indicates that there is no critical point.

The topological and geometrical parameters characterizing the interactions between water and DAC molecules in the $S_{1}$ and $S_{2}$ isomers clearly suggests that two non-covalent hydrogen bondings are formed in both cases $[17,58]$. However, the interactions involved in the $S_{3}$ isomer are of different nature: in addition with a "classical" non-covalent hydrogen bonding $\left(\mathrm{H}_{\text {water }}-\mathrm{O}_{\text {carbonyl }}\right)$, another electrostatically-driven interaction $\left(\mathrm{O}_{\text {water }}-\mathrm{O}_{\text {carbonyl }}\right)$ also stabilizes the complex.

\section{Characterization of the isomers in terms of orbital overlapping}

To further characterize the interactions between the DAC and the water molecules in each of the three isomers, an NBO study was carried out [59-61]. The HOMO and LUMO orbitals leading to a constructive overlap between the water molecules and the oxygen atom of the carbonyl group are presented in Figure 8. For the $S_{1}$ and $S_{2}$ isomers (Figure 8A and 8B, respectively), similar orbital overlaps are involved in the interaction: the stabilization is due to a charge transfer between $\sigma$ molecular orbitals from an oxygen carbonyl atom and an hydrogen atom of the water molecule. In addition with this overlapping, the interaction between the water oxygen atom and one or two carbonyl hydrogen atoms (for $S_{1}$ and $S_{2}$, respectively), are fully consistent with classical description of hydrogen bondings.

The interaction involved in the $\mathrm{S}_{3}$ isomer (Figure 8C) is clearly different: in this case, an oxygen carbonyl atom and the water oxygen atom interact through a charge transfer between a $\pi$ molecular orbital involving the carbon atom of the carbonyl group and a $\sigma$ molecular orbital of the water oxygen atom (Figure $8 \mathrm{C}_{1}$ ). The molecular orbital overlapping is similar to the one that was calculated for the case of the most stable $\mathrm{SiO} / \mathrm{H}_{2} \mathrm{O}$ isomer (Figure 7B), from a $\sigma(\mathrm{O})$ orbital of the water molecule, to a $\pi^{*}(\mathrm{CO})$ orbital. Additionally, Figure $8 \mathrm{C}_{2}$ presents the NBO overlapping involved in the interaction between the water oxygen atom and a methyl hydrogen atom. 


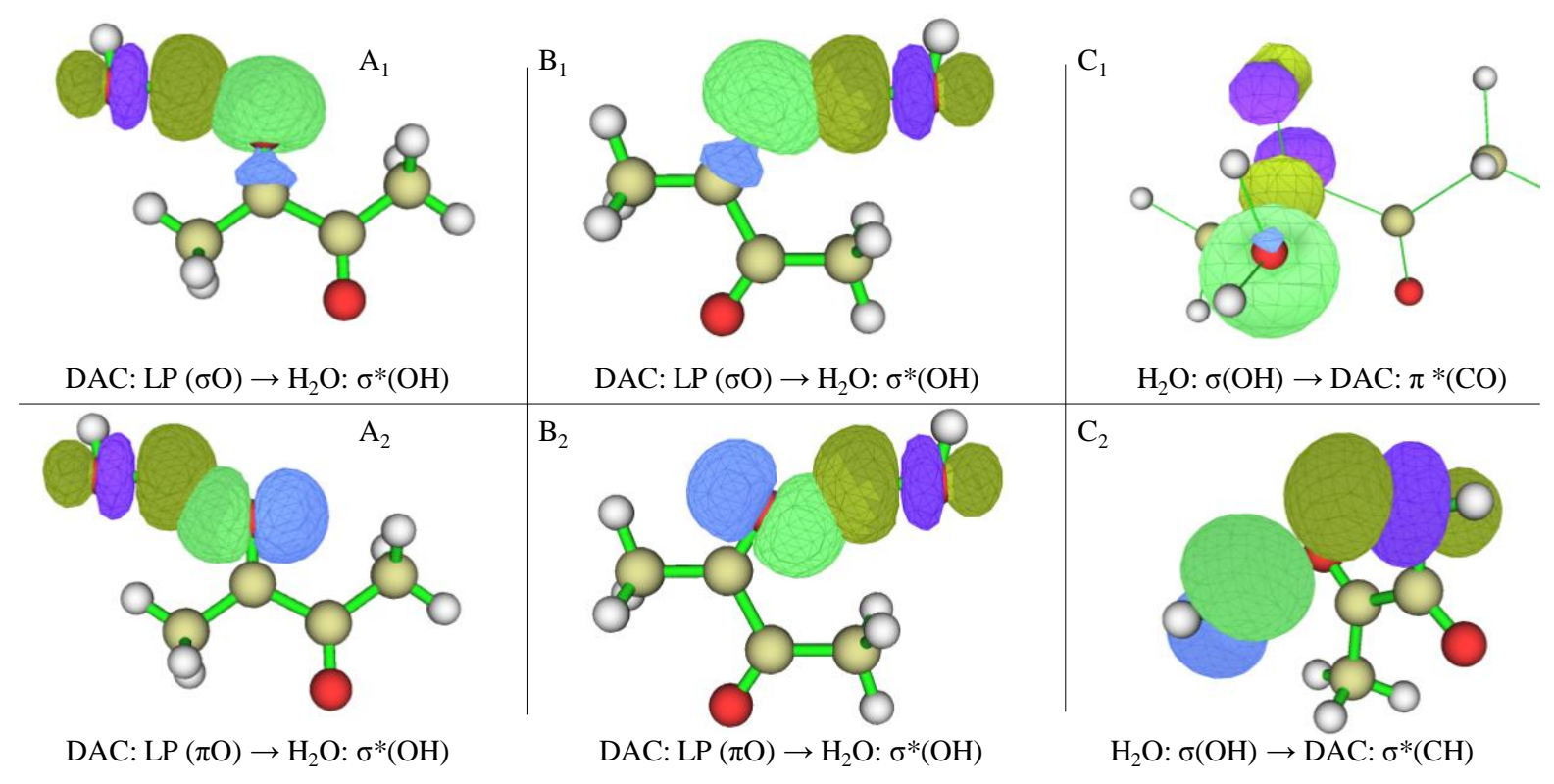

Figure 8: Schematic representation of the HOMO and LUMO molecular orbitals involved in the stabilization of the three 1/1 : $\mathrm{DAC} / \mathrm{H}_{2} \mathrm{O}$ isomers. Constructive overlap between the water molecules and the oxygen atom of the carbonyl group for the $A: S_{1} ; B: S_{2}$ and $C: S_{3}$ isomers. The orbitals involved are mentioned under each pictures (Donor $\rightarrow$ Acceptor).

\section{Conclusion}

Geometries of the 1/1 : $\mathrm{DAC} / \mathrm{H}_{2} \mathrm{O}$ isomers were re-investigated. To this end, a systematic topological analysis using complementary approaches - MESP, QTAIM and ELF was proposed. To begin with, a thorough characterization of isolated monomers allowed an accurate identification of complementary reaction sites in the two partners. From this preliminary step, it was possible to consider an isomeric form not yet reported in the literature for this complex.

Finally, three different isomers were optimized. A further geometric, energetic and topologic characterization of each of the isomers shows that:

$>$ in the first two cases (S1 and S2), the formation of the complex involves traditional non-covalent hydrogen bondings,

$>$ in the third case (S3), in addition with a traditional non-covalent hydrogen bonding, another non-covalent interaction is involved in the formation of the complex. This additional non-covalent interaction is of similar nature than the one involved in isomeric forms of $1 / 1: \mathrm{CO} / \mathrm{H}_{2} \mathrm{O}$ and $1 / 1: \mathrm{SiO} / \mathrm{H}_{2} \mathrm{O}$. 
Each of the 1/1:DAC/ $\mathrm{H}_{2} \mathrm{O}$ isomer has a cyclic structure in which two complementary interactions are involved. We would like to underline that the three isomers are almost isoenergetic.

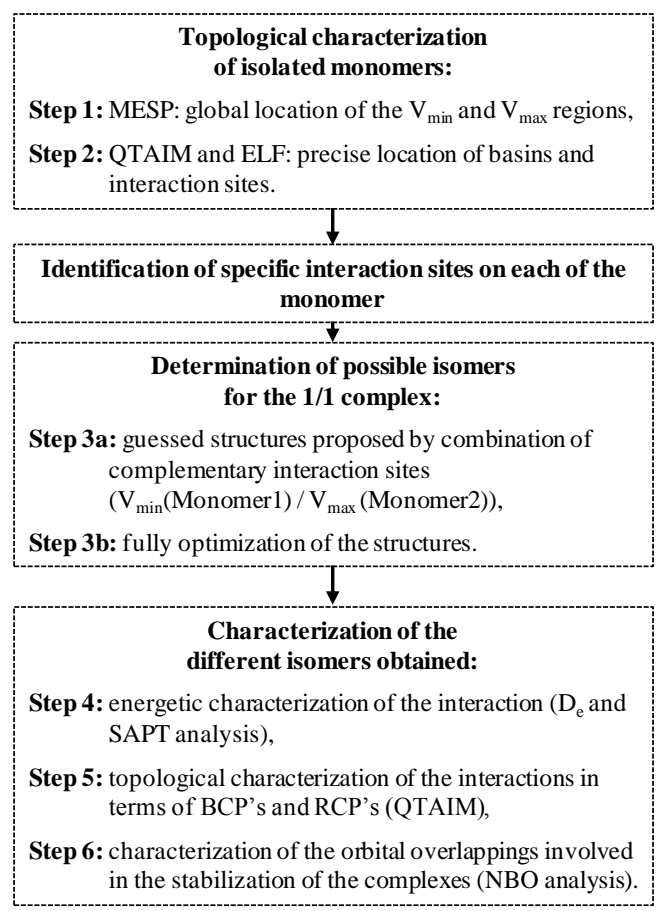

Figure 9: Schematic representation of the methodology herein proposed for the study of $1 / 1$ hydrated complexes.

The methodological study herein proposed is summed up in the Figure 9. We are convinced that the use of such an approach may help in characterizing all the possible isomers for non-covalent 1/1 complexes, in the case of hydrated species and beyond.

\section{Computational details}

Explicitly correlated coupled clusters calculations (CCSD(T)-F12) were carried out using the Molpro2010.1 package [62]. Second order Møller-Plesset (MP2) calculations have been performed using the Gaussian09 package [63]. Dunning and coworkers augmented correlation consistent basis set aug-cc-pVDZ (labeled as AVDZ in our text) and aug-cc-pVTZ (labeled as AVTZ in our text) have been used.[64,65] All geometry optimizations were performed with «tight » convergence criteria.

SAPT-DFT analysis were performed with Molpro at PBE0 level of theory with 6$311++\mathrm{G}(2 \mathrm{~d}, 2 \mathrm{p})$ basis set [66].

AIMAll software was used for the quantitative study of the topological QTAIM data.[67] The ELF calculations have been done using TopMod software [68]. All the 
necessary wfn files for the topological investigations have been obtained using Gaussian09 with "Density = Current" option at MP2/AVTZ level of theory for monomers and CCSD/AVTZ with CCSD(T)-F12/AVDZ geometry (CCSD/AVTZ//CCSD(T)-F12/AVDZ) for $1 / 1$ : DAC/Water isomers.

NBO [69] analysis has been performed using NBO5.0 program at the SCF function obtained at CCSD/AVTZ//CCSD(T)-F12/AVDZ level of theory. 


\section{References}

${ }^{1}$ a) D. Philip, J.F. Stoddart, Angew Chem Int Ed. 35, 1154 (1996); b) G.R. Desiraju, J. Am. Chem. Soc. 135, 9952 (2013); c) C.A. Hunter, Angew. Chem. Int. Ed. 43, 5310 (2004); d) P. Hobza, K. Müller-Dethlefs. Non-covalent interactions: Theory and experiments (RSC Publishing, 2009). e) G.R. Desiraju, T. Steiner. The weak hydrogen bond in structural chemistry and biology (Oxford University Press, Oxford, 1999); f) Hydrogen bonding: New Insights. Challenges and advances in computational chemistry and physics, Volume 3. S.J. Grabowski. Edited by Leszczynski (Springer. 2006)

2 a) T.S. Moore, T.F. Winmill, J. Chem. Soc. T. 101, 1635 (1912); b) L. Pauling. The nature of the chemical bond Cornell (University Press, Ithaca, NY, 1939); c) E. Arunan, G.R. Desiraju, R.A. Klein, J. Sadlej, S. Scheiner, I. Alkorta, D.C. Clary, R.H. Crabtree, J.J. Dannenberg, P. Hobza, H.G. Kjaeergaard, A.C. Legon, B. Mennucci, D.J. Nesbitt, Pure Appl. Chem. 83, 1619 (2011); d) E. Arunan, G.R. Desiraju, R.A. Klein, J. Sadlej, S. Scheiner, I. Alkorta, D.C. Clary, R.H. Crabtree, J.J. Dannenberg, P. Hobza, H.G. Kjaeergaard, A.C. Legon, B. Mennucci, D.J. Nesbitt, Pure Appl. Chem. 83, 1637 (2011)

${ }^{3}$ S. J. Grabowski, J. Phys. Chem. A 105, 10739 (2001)

${ }^{4}$ I. Rozas, Phys. Chem. Chem. Phys. 9, 2782 (2007)

5 J. G. Hill, A. C. Legon, Phys. Chem. Chem. Phys. 17, 858 (2015)

${ }^{6}$ For a discussion on the estimation of hydrogen bonding energies in the case of intramolecular interactions, see for example: D. Rusinska-Roszak, G. Sowinski, Journal of Chemical information and Modeling. 54, 1963 (2014)

${ }^{7}$ B. Jeziorski, R. Moszynski, K. Szalewicz, Chem. Rev. 94, 1887 (1994)

${ }^{8}$ R. Moszynski, T. G. A. Heijmen, B. Jeziorski, Mol. Phys. 88, 741 (1996)

9 A. J. Misquitta, R. Podeszwa, B. Jeziorski, K. Szalewicz, J. Chem. Phys. 123, 214103 (2005)

${ }^{10}$ S. Scheiner, Int. J. Quant. Chem. 113, 1609 (2013)

${ }^{11}$ J.S. Murray, P. Lane, P. Politzer, J. Mol. Model. 15, 723 (2009)

${ }^{12}$ M.D. Esrafili, M. Vakili, J. Mol. Model. 20, 2291 (2014)

${ }^{13}$ P. Politzer, J.S. Murray, T. Clark, Phys. Chem. Chem. Phys., 12 , 7748 (2010)

${ }^{14}$ M. Hennemann, J.S. Murray, P. Politzer, K.E. Riley, T. Clark, J. Mol. Model. 18, 2461 (2012)

15 J. S. Murray, M/C. Concha, P. Lane, P. Hobza, P. Politzer, J. Mol. Model. 14, 699 (2008)

${ }^{16}$ T. Clark, WIREs Comput Mol Sci, 3, 13 (2013) 
${ }^{17}$ S.J. Grabowski, W.A. Sokalski, E. Dyguda, J. Leszczynski, J. Phys. Chem. B, 110, 6444 (2006)

${ }^{18}$ S.J. Grabowski, Chem. Eur. J. 19, 14600 (2013)

${ }^{19}$ P. Politzer, J.S. Murrray, Theor. Chem. Acc. , 108, 134 (2002)

${ }^{20}$ P. Politzer, J.S. Murray, G.V. Janjic, S.D. Zaric, Crystals 4, 12 (2014)

${ }^{21}$ J.S. Murray, P. Lane, T. Clark, K.E. Riley, P. Politzer, J. Mol. Model. 18, 541 (2012)

${ }^{22}$ J. Hoja, A.F. Sax, K. Szalewicz, Chem. Eur. J., 20, 2292 (2014)

${ }^{23}$ R. F. Bader, Atoms in Molecules: A Quantum Theory (Oxford University Press, Oxford, 1994)

${ }^{24}$ R. F. W. Bader, J. Phys. Chem. A, 102, 7314 (1998)

${ }^{25}$ Y. Mo, J. Phys. Chem. A 116, 5240 (2012)

${ }^{26}$ A. D. Becken K. E. Edgecombe, J. Chem. Phys., 92, 5397 (1990)

${ }^{27}$ B. Silvi A. Savin, Nature, 371, 683 (1994)

${ }^{28}$ P. Fuentealba, E. Chamorro, J.C. Santo. Understanding and using the electron localization function. In Theoretical aspects of Chemical Reactivity. A. Torro-Labbé, (Elsevier 2006)

${ }^{29}$ A. Savin, B. Silvin F. Colonna, Can. J. Chem. 74, 1088 (1996)

${ }^{30}$ B. Silvi, I. Fourrén M. E. Alikhani, Monatshefte für Chemie 136, 855 (2005)

${ }^{31}$ B. Silvi, J. Phys. Chem. A. 107, 3081 (2003)

${ }^{32}$ M.E. Alikhani, F. Fuster, B. Silvi, Struc. Chem. 16, 203 (2005)

${ }^{33}$ F. Fuster, B. Silvi, Theor. Chem. Account. 104, 13 (2000)

${ }^{34}$ F. Fuster, S. J. Grabowski, J. Phys. Chem. A. 115, 10078 (2011)

${ }^{35}$ W. Klöpffer, B.O. Wagner, Wiley VCH. John Wiley \& Sons, 2008

${ }^{36}$ J.C. Calvert, A.Mellouki, J.J. Orlando, The mechanisms of atmospheric oxidation of the oxygenates (Oxford University Press, 2011)

${ }^{37}$ V. Vaida, J. Phys. Chem. A. 113, 5 (2009)

${ }^{38}$ Y. M. Li, J. S. Francisco, J. Am. Chem. Soc. 127, 12144 (2005)

${ }^{39}$ R. J. Buszek, J.S. Francisco, J. M. Anglada, Int. Rev. Phys. Chem. 30, 335 (2011)

${ }^{40}$ B. Klotz, F. Graedler, S. Sørensen, I. Barnes, K. H. Becker, Int. J. Chem. Kinetics. 33, 9 (2001)

${ }^{41}$ S. Aloisio, J.S. Francisco, Phys. Chem. Earth (C). 25, 245 (2000)

${ }^{42}$ M. Mucha, Z. Mielke, J. Phys. Chem. A. 111, 2398 (2007)

${ }^{43}$ L. B. Favero, W. Caminati, J. Phys. Chem. A. 113, 14308 (2009) 
${ }^{44}$ M. Cirtog, M.E. Alikhani, B. Madebène, P. Soulard, P. Asselin, B. Tremblay, J. Phys. Chem. A. 115, 6688 (2011)

${ }^{45}$ M. D. Esrafili, J. Mol. Model. 18, 5005 (2012)

${ }^{46}$ For other complementary approaches, see also:

a) F. Weinhold, R.A. Klein, Mol. Phys. 110, 565 (2012)

b) S. Scheiner, U. Adhikari, J. Phys. Chem. A. 115, 11101 (2011)

c) B.G. Oliveira, Struct. Chem. 25, 745 (2014)

d) S.J. Grabowski, Theor. Chem. Acc. 132, 1347-1 (2013)

e) B. Bankiewicz, P. Matczak, M. Palusiak, J. Phys. Chem. A. 116, 452 (2012)

${ }^{47}$ Y. Zhang, D.S. Hollman, H.F. Schaeffer III, J. Chem. Phys. 136, 244305-1 (2012)

${ }^{48}$ See also: R.J. Wheatley, A.H. Harvey, J. Chem. Phys. 131, 154305-1 (2009)

${ }^{49}$ T. Clark, M. Hennemann, J.S. Murray, P. Politzer, J. Mol. Model. 13, 291 (2007)

${ }^{50}$ S. Scheiner, Int. J. Quant. Chem. 113, 1609 (2013)

${ }^{51}$ P. Politzer, J. S. Muray, T. Clark, Phys. Chem. Chem. Phys. 15, 11178, (2013)

${ }^{52}$ A. Kumar, S. R. Gadre, N. Mohan, C. H. Suresh, J. Phys. Chem. A 118, 526 (2014)

${ }^{53}$ F. Fuster. PhD Thesis, Caractérisation des sites réactifs à partir de l'analyse topologique de fonctions locales (Université Pierre et Marie Curie, 1999)

${ }^{54}$ T. B. Adler, G. Knizia, H.-J. Werner, J. Chem. Phys. 127, 221106 (2007)

${ }^{55}$ J. Noga, S. Kedzuch, J. Simunek, S. Ten-No, J. Chem. Phys. 128, 174103 (2008)

${ }^{56}$ See supplementary material at http://dx.doi.org/xxxxx for the cartesian coordinates of monomers and S1, S2 and S3 isomers of the 1/1 : DAC/Water complex optimized at both MP2/AVTZ and CCSD(T)-F12/AVDZ level of theory.

${ }^{57}$ We further investigated the reason for this particular location of the BCP, and an article is in preparation on this topic, in line with the Shahbazian's work. See for instance: a) C. Foroutan-Nejad, S. Shahbazian, R. Marek, Chem. Eur. J. 20, 10140 (2014); b) P. Nasertayoob, S. Shahbazian, International Journal of Quantum Chemistry. 108, 1477 (2008);

c) S. Shahbazian, Found. Chem. 15, 287 (2013)

${ }^{58}$ S.J. Grabowski, Chem. Rev. 111, 2597 (2011)

59 E.D. Glendening, C.R. Landis, F. Weinhold, Natural bond orbital methods (Wiley Interdisciplinary Reviews: Computational Molecular Science, 2012)

${ }^{60}$ F. Weinhold, R. A. Klein, Chem. Educ. Res. Pract. 15, 276 (2014)

${ }^{61}$ F. Weinhold, C. R. Landis, Chem. Educ. Res. Pract. 2, 91 (2001) 
$\overline{{ }^{62} \text { MOLPRO, version 2010.1, a package of ab initio programs, H.-J. Werner, P. J. Knowles, }}$ G. Knizia, F. R. Manby, M. Schütz, P. Celani, T. Korona, R. Lindh, A. Mitrushenkov, G. Rauhut, K. R. Shamasundar, T. B. Adler, R. D. Amos, A. Bernhardsson, A. Berning, D. L. Cooper, M. J. O. Deegan, A. J. Dobbyn, F. Eckert, E. Goll, C. Hampel, A. Hesselmann, G. Hetzer, T. Hrenar, G. Jansen, C. Köppl, Y. Liu, A. W. Lloyd, R. A. Mata, A. J. May, S. J. McNicholas, W. Meyer, M. E. Mura, A. Nicklass, D. P. O'Neill, P. Palmieri, K. Pflüger, R. Pitzer, M. Reiher, T. Shiozaki, H. Stoll, A. J. Stone, R. Tarroni, T. Thorsteinsson, M. Wang, and A. Wolf, , see http://www.molpro.net.

${ }^{63}$ M. J. Frisch, G. W. Trucks, H. B. Schlegel, G. E. Scuseria, M. A. Robb, J. R. Cheeseman, G. Scalmani, V. Barone, B. Mennucci, G. A. Petersson, H. Nakatsuji, M. Caricato, X. Li, H. P. Hratchian, A. F. Izmaylov, J. Bloino, G. Zheng, J. L. Sonnenberg, M. Hada, M. Ehara, K. Toyota, R. Fukuda, J. Hasegawa, M. Ishida, T. Nakajima,Y. Honda, O. Kitao, H. Nakai, T. Vreven, J. A. Montgomery, Jr., J. E. Peralta, F. Ogliaro, M. Bearpark, J. J. Heyd, E. Brothers, K. N. Kudin, V. N. Staroverov, R. Kobayashi, J. Normand, K. Raghavachari, A. Rendell, J. C. Burant, S. S. Iyengar, J. Tomasi, M. Cossi, N. Rega, J. M. Millam, M. Klene, J. E. Knox, J. B. Cross, V. Bakken, C. Adamo, J. Jaramillo, R. Gomperts, R. E. Stratmann, O. Yazyev, A. J. Austin, R. Cammi, C. Pomelli, J. W. Ochterski, R. L. Martin, K. Morokuma, V. G. Zakrzewski, G. A. Voth, P. Salvador, J. J. Dannenberg, S. Dapprich, A. D. Daniels, Ö. Farkas, J. B. Foresman, J. V. Ortiz, J. Cioslowski, and D. J. Fox, Gaussian 09, Revision D.01, Gaussian, Inc., Wallingford, CT, 2009.

${ }^{64}$ T. H. Jr. Dunning, J. Chem. Phys. 90, 1007 (1989)

${ }^{65}$ R.A. Kendall, T.H. Dunning, R.J. Harrison, J. Chem. Phys. 96, 6796 (1992)

${ }^{66}$ a) R. Krishnan, J.S. Binkley, R. Seeger, J. A. Pople, J. Chem. Phys. 72, 650 (1980); b) M.J. Frisch, J.A. Popl, J.S. Binkley, J. Chem. Phys. 80, 3265 (1984); c) T. Clark, J. Chandrasekhar, G.W. Spitznagel, P.V.R. Schleyer, J. Comp. Chem. 4, 294 (1983)

${ }^{67}$ T. A. Keith, AIMAll (Version 14.10.27), TK Gristmill Software, Overland Park KS, USA, 2014 (aim.tkgristmill.com)

${ }^{68}$ S. Noury, X. Krokidis, F. Fuster, B. Silvi, Comput. Chem., 23, 597 (1999)

${ }^{69}$ NBO 5.0. E. D. Glendening, J, K. Badenhoop, A. E. Reed, J. E. Carpenter, J. A. Bohmann, C. M. Morales, F. Weinhold, Theoretical Chemistry Institute, University of Wisconsin, Madison (2001). 


\section{Supplementary material SM1:}

\section{Optimized monomers structures}

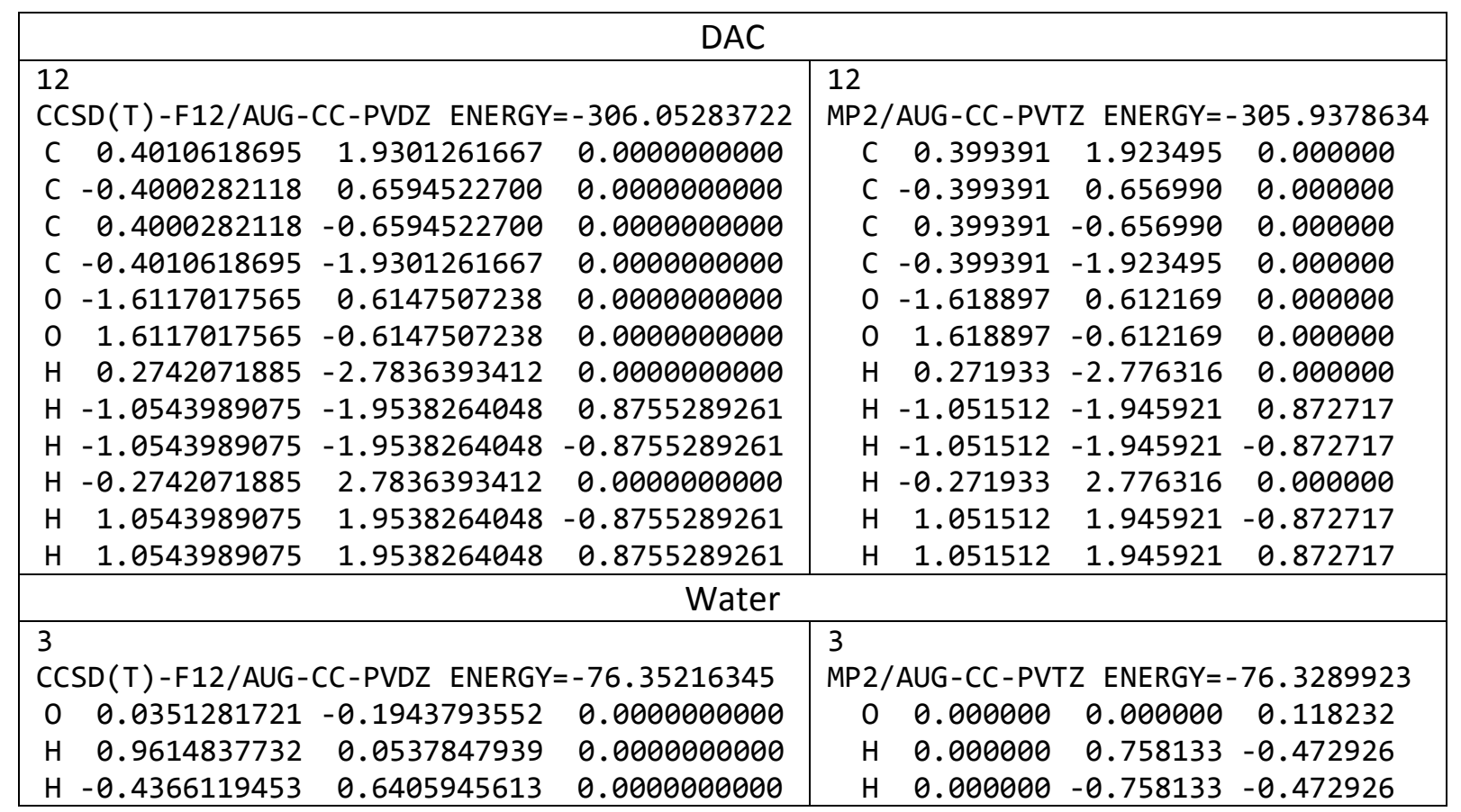

\section{Optimized 1/1 complex structures}

\begin{tabular}{|c|c|c|c|c|c|}
\hline \multicolumn{6}{|c|}{ DAC Water 11 complex : S1 } \\
\hline \multicolumn{3}{|c|}{15} & \multicolumn{3}{|l|}{15} \\
\hline $\operatorname{CCSD}(T)-F 12 / A U G-C C$ & -PVDZ ENERGY= & -382.41436484 & MP2/AUG-CC-PVTZ & ENERGY $=-$ & 382.2762575 \\
\hline C -2.1185808624 & -1.3384910390 & 0.0000000000 & C 1.866255 & -1.65502 & 0.000000 \\
\hline C -1.5210924345 & 0.0396154665 & 0.0000000000 & 1.501659 & -0.20275 & 0.000000 \\
\hline C 0.0194787424 & 0.1247549995 & 0.0000000000 & C 0.000000 & $0.12924 \epsilon$ & 0.000000 \\
\hline C $\quad 0.6226965681$ & 1.4962957318 & 0.0000000000 & C -0.371364 & 1.57557 & 0.000000 \\
\hline $0-2.1656885488$ & 1.0656691360 & 0.0000000000 & $0 \quad 2.309640$ & 0.710836 & 0.000000 \\
\hline $0 \quad 0.6566129056$ & -0.9120091727 & 0.0000000000 & $0-0.801931$ & -0.79607 & 0.000000 \\
\hline 3.4672136488 & -0.2502824026 & 0.0000000000 & $0-3.458811$ & 0.30093 & 0.000000 \\
\hline 1.7089104589 & 1.4296705967 & 0.0000000000 & H -1.450896 & 1.68958 & 0.000000 \\
\hline H 0.2654833839 & 2.0460241752 & -0.8745881131 & H 0.070712 & 2.05839 & 0.871615 \\
\hline H 0.2654833839 & 2.0460241752 & 0.8745881131 & 0.070712 & 2.05839 & -0.871615 \\
\hline H -3.2040853083 & -1.2608869984 & 0.0000000000 & 2.946783 & -1.75664 & 0.000000 \\
\hline H -1.7713341047 & -1.8916573366 & 0.8760198670 & 1.433884 & -2.142815 & -0.873239 \\
\hline H -1.7713341047 & -1.8916573366 & -0.8760198670 & 1.433884 & -2.14281 & 0.873239 \\
\hline H 2.6131509023 & -0.7013222409 & 0.0000000000 & H -2.672234 & -0.26573 & 0.000000 \\
\hline 4.1238313693 & -0.9482277538 & 0.0000000000 & H -4.203328 & -0.30612 & 0.000000 \\
\hline \multicolumn{6}{|c|}{ DAC_Water 1_1 complex : S2 } \\
\hline
\end{tabular}




\begin{tabular}{|c|c|c|c|c|c|c|}
\hline \multicolumn{3}{|l|}{15} & \multicolumn{4}{|l|}{15} \\
\hline \multicolumn{3}{|c|}{$\operatorname{CCSD}(T)-F 12 / A U G-C C-P V D Z \quad E N E R G Y=-382.41439971$} & \multicolumn{4}{|c|}{ MP2/AUG-CC-PVTZ ENERGY=-382.2763011 } \\
\hline C 0.0018572145 & 0.0000000000 & -0.0060469431 & C & 0.691760 & -1.557766 & 0.000000 \\
\hline C -0.0002714311 & 0.0000000000 & 1.4931373893 & $\mathrm{C}$ & 1.114969 & -0.124791 & 0.000000 \\
\hline C $\quad 1.3720337237$ & 0.0000000000 & 2.2017711032 & $\mathrm{C}$ & 0.000000 & 0.936355 & 0.000000 \\
\hline 1.3514037447 & 0.0000000000 & 3.7013003464 & $\mathrm{C}$ & 0.438409 & 2.365475 & 0.000000 \\
\hline $0-0.9990723581$ & 0.0000000000 & 2.1807764578 & 0 & 2.274559 & 0.256214 & 0.000000 \\
\hline $0 \quad 2.3934247129$ & 0.0000000000 & 1.5432912425 & 0 & -1.172148 & 0.588093 & 0.000000 \\
\hline 2.8872068900 & 0.0000000000 & -0.3567329747 & $\mathrm{H}$ & -2.170633 & -1.079667 & 0.000000 \\
\hline 2.9424444767 & 0.0000000000 & -1.3199835853 & 0 & -2.507644 & -1.987204 & 0.000000 \\
\hline 3.8811170161 & 0.0000000000 & -1.5139939606 & $\mathrm{H}$ & -3.463653 & -1.891014 & 0.000000 \\
\hline 0.5409967171 & 0.8724261312 & -0.3837388464 & $\mathrm{H}$ & 0.068685 & -1.766868 & 0.869645 \\
\hline 0.8040915136 & 0.8749769193 & 4.0600382566 & $\mathrm{H}$ & 1.063554 & 2.554956 & 0.872189 \\
\hline H $\quad 2.3718216437$ & 0.0000000000 & 4.0793149862 & $\mathrm{H}$ & -0.431282 & 3.014571 & 0.000000 \\
\hline H -1.0255200944 & 0.0000000000 & -0.3650818820 & $\mathrm{H}$ & 1.572124 & -2.192531 & 0.000000 \\
\hline H $\quad 0.5409967171$ & -0.8724261312 & -0.3837388464 & $\mathrm{H}$ & 0.068685 & -1.766868 & -0.869645 \\
\hline 0.8040915136 & -0.8749769193 & 4.0600382566 & $\mathrm{H}$ & 1.063554 & 2.554956 & -0.872189 \\
\hline \multicolumn{7}{|c|}{ DAC_Water 1_1 complex : S3 } \\
\hline \multicolumn{3}{|c|}{15} & \multicolumn{4}{|c|}{15} \\
\hline \multicolumn{3}{|c|}{$\operatorname{CCSD}(T)-F 12 / A U G-C C-P V D Z \quad E N E R G Y=-382.41323957$} & \multicolumn{4}{|c|}{ MP2/AUG-CC-PVTZ ENERGY $=-382.2751655$} \\
\hline C 1.0328197678 & -0.1011371508 & -0.0903128496 & C & -0.618236 & -0.825255 & -0.340688 \\
\hline C -0.1759026278 & 0.6757948613 & 0.4701338436 & $\mathrm{C}$ & 0.733146 & -0.379281 & 0.240984 \\
\hline $0 \quad 1.7144586217$ & 0.4170946721 & -0.9487850780 & 0 & -0.645478 & -1.318659 & -1.456424 \\
\hline $0-0.7697559252$ & 0.2405566031 & 1.4360753970 & 0 & 0.798041 & -0.025081 & 1.409078 \\
\hline C 1.2863204990 & -1.4629357269 & 0.4872630729 & C & -1.821643 & -0.619919 & 0.523775 \\
\hline$C-0.5376598682$ & 1.9467836620 & -0.2393877709 & C & 1.900272 & -0.409929 & -0.692773 \\
\hline H $\quad 2.2086434481$ & -1.8651799603 & 0.0720112698 & $\mathrm{H}$ & -2.691512 & -1.056642 & 0.043203 \\
\hline H $\quad 0.4411774504$ & -2.1096468937 & 0.2387564041 & $\mathrm{H}$ & -1.963750 & 0.451465 & 0.667572 \\
\hline H 1.3402538690 & -1.4045796855 & 1.5763591825 & $\mathrm{H}$ & -1.656534 & -1.057931 & 1.506864 \\
\hline H -0.8188172098 & 1.7051987735 & -1.2677666485 & $\mathrm{H}$ & 1.710452 & 0.285901 & -1.510473 \\
\hline H $\quad 0.3310207014$ & 2.6059364717 & -0.2942972324 & $\mathrm{H}$ & 1.996453 & -1.399255 & -1.137330 \\
\hline H - 1.3640818304 & 2.4306994071 & 0.2781599068 & $\mathrm{H}$ & 2.803510 & -0.131568 & -0.158891 \\
\hline $0-1.8185177699$ & -1.2565153866 & -0.8512142578 & 0 & -0.237998 & 2.335733 & 0.071392 \\
\hline H - -2.5275703817 & -1.6727809405 & -1.3452571192 & $\mathrm{H}$ & -0.254247 & 3.294542 & -0.002322 \\
\hline H -2.1695057443 & -1.1213367065 & 0.0335998796 & $\mathrm{H}$ & 0.188235 & 2.157127 & 0.917677 \\
\hline
\end{tabular}

